\title{
Por um antropomorfismo dilacerado: Georges Bataille e a arte contemporânea
}

\author{
TADEU RIBEIRO *
}

\begin{abstract}
RESUMO Este artigo explora a noção de antropomorfismo dilacerado - proposta por Georges Bataille no fim da década de 1930 em sua obra O Culpado - para propor possibilidades de leitura e reflexão sobre o processo de transformação das representações antropomórficas na arte contemporânea. Desde o modernismo, tais alterações se apresentam como sintomas de desgaste dos princípios humanistas da representação, rompendo com os ideais clássicos da composição pictórica e abrindo o campo das imagens para a insurgência de corpos atravessados por violências - rupturas, dilacerações, despedaçamentos - e corpos não-normativos - cuja subversão produz tensões. Para pensar funcionamentos e perspectivas possíveis do corpo fragmentado na arte contemporânea, apresento um conjunto de ideias desenvolvidas por Bataille, articulando-as a poéticas da arte contemporânea.
\end{abstract}

PALAVRAS-CHAVE antropomorfismo dilacerado, Georges Bataille, arte contemporânea

\section{AS PERNAS DE DAVI}

Dispostas em sequência numa parede, doze fotografias de dimensão antropomórfica apresentam um modelo nu posando sobre um pedestal em estúdio ${ }^{1}$. Trata-se da obra David (figura 1), do artista colombiano Miguel Ángel Rojas, na qual vemos o soldado José Antonio - cuja parte inferior da perna esquerda fora mutilada por uma mina terrestre - reencenando os gestos da escultura homônima de Michelangelo (figura

* Programa de Pós-Graduação em Estudos Contemporâneos das Artes (UFF/mestrado) Bolsista CAPES

1 A obra é composta por um conjunto de doze fotografias em preto e branco medindo $200 \times 100 \mathrm{~cm}$ cada uma. 
2). A trama de relações que se estabelecesse entre os dois trabalhos, evocada deliberadamente pela data de produção da última (apresentada no quinto centenário do primeiro Davi), insurge como sintoma de uma alteração radical nas concepções ocidentais de corpo, imagem e representação. De Michelangelo a Miguel Ángel, o corpo marmóreo e asséptico idealizado na Florença quinhentista - em sua condensação plástica das premissas humanistas que permearam o Renascimento no século XVI é reapropriado na Bogotá do século XXI, onde é atravessado por questões de etnia, colonização e narcotráfico.

O herói bíblico representado por Michelangelo, composto em volume monumental, articula os princípios para formulação de corpos que predominavam na ascensão do cinquecento: a assimilação de referências da Antiguidade Clássica, explícita em autores como Leon Battista Alberti, fundamentava a busca antropocêntrica por um corpo cuja beleza apoiava-se nas noções de harmonia e proporção. Em De re aedificatoria, tratado publicado em 1450, Alberti concebe o Belo como "uma correspondência tal entre as partes e o todo que nada pode ser acrescentado, subtraído ou alterado sem
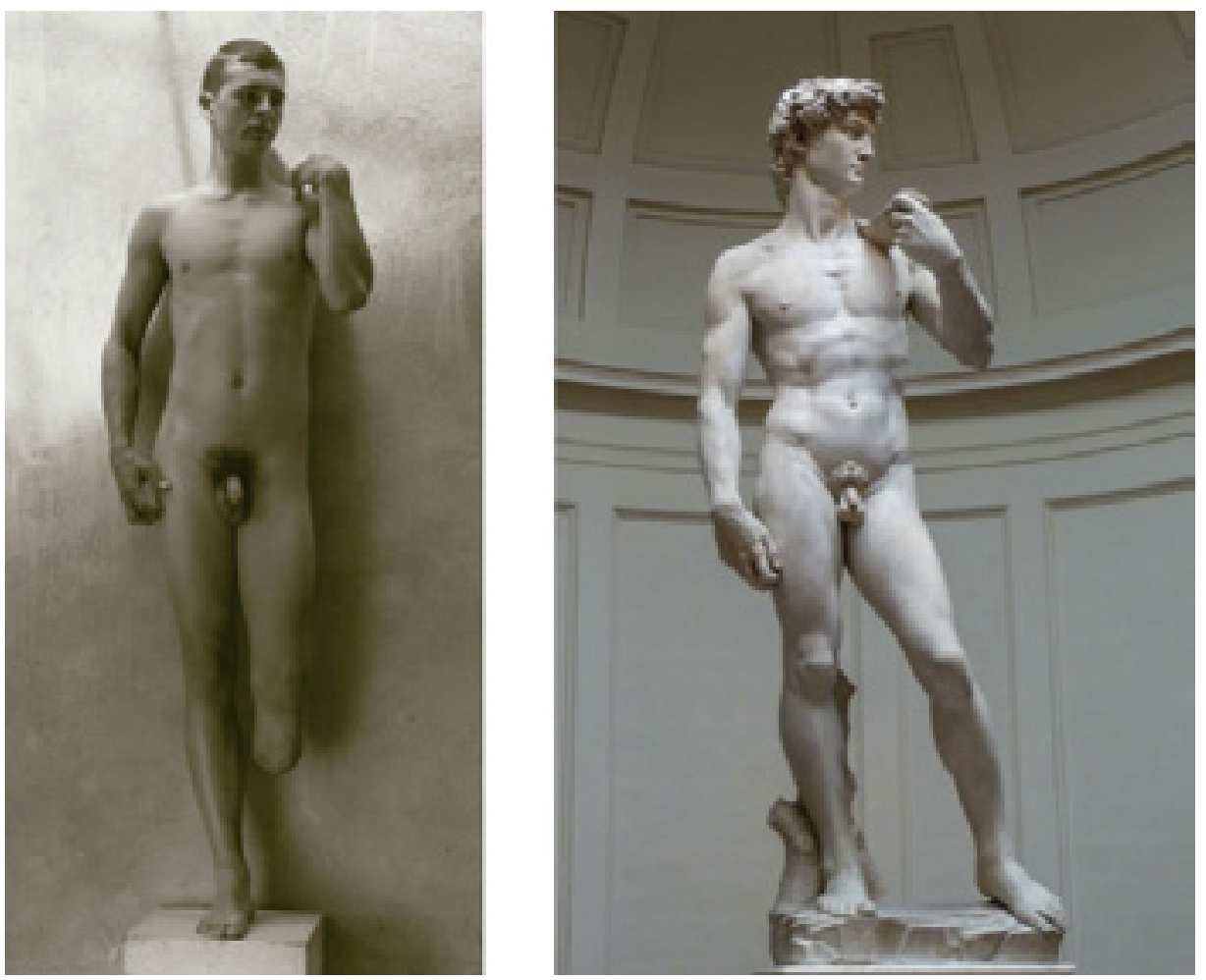

Figura 1. David, Miguel Ángel Rojas, 2005

Figura 2. Davi, Michelangelo, 1501-4 
comprometer a unidade do conjunto" (D'AGOSTINO, 2003, p.115). O corpo masculino ideal, isto é, o homem universal - branco, europeu, moderadamente musculoso - dava carne à convicção do imaginário renascentista na máxima de Protágoras: o homem (embora não qualquer humano) é a medida de todas as coisas. A construção matemática desse corpo evidencia o vínculo idealista entre imagem e moral - a convergência entre valores éticos e estéticos: bom, belo e verdadeiro (kalokagathia). Não por acaso, a alguns minutos da escultura de Michelangelo, situa-se o palácio que abriga a Accademia delle Arti del Disegno, que, criada em 1562, marca a primazia do desenho como projeto e estruturação de uma ideia que deveria reger a composição de imagens a partir da razão. Neste contexto, a busca pela perfeição do corpo representado é atravessada por um conjunto de noções que emergem como marca da concepção idealista na criação de imagens.

Se para o cânone renascentista seria inconcebível representar um corpo com alguma deficiência - uma vez que esta característica perverteria seu esquema moralizante e racionalista -, este elemento é o ponto culminante de perturbação do olhar na obra do colombiano. No entanto, apesar da ausência parcial de um dos membros inferiores, que lhe impossibilita o contrapposto (tradicional posição escultórica na qual o corpo apoia-se sobre uma das pernas, distribuindo seu peso e tornando a composição mais harmônica e naturalista), o corpo mantém-se de pé. Se a razão que rege a noção clássica do Belo marginaliza determinadas possibilidades de corpos, tornando-as imagens subversivas e violentas, a contemporaneidade resgata caminhos escamoteados da representação, reinserindo corpos grotescos, monstruosos e marginalizados em suas poéticas sob um novo viés. O antropomorfismo ressurge, a cada transgressão, como outro. Mata-se a ideia de homem para que outros corpos possam surgir. O sujeito desencarnado da representação clássica, na qual a ideia se sobrepõe à carne, é posto em xeque numa operação dilacerante.

\section{DOCUMENTS: ARQUIVOS DA DILACERAÇÃO}

Um eminente químico inglês, o Dr. Charles Henry Maye, empenhou-se em estabelecer de forma exata de que é feito o homem e qual é seu valor químico. Eis os resultados de suas sábias pesquisas. A gordura de um corpo humano de constituição normal seria suficiente para fabricar sete porções de sabonete. Encontram-se no seu organismo quantidades suficientes de ferro para fabricar um prego de espessura média e de açúcar para adoçar uma xícara de café. O fósforo daria para 2.200 palitos de fósforo. O mag- 
nésio forneceria matéria para se tirar uma fotografia. Ainda um pouco de potássio e de enxofre, mas quantidade inutilizável. Essas diversas matérias-primas, avaliadas na moeda corrente, representam uma soma em torno de 25 francos $^{2}$.

O perturbador cálculo de decomposição química do corpo proposto pelo cientista fictício sugere uma indistinção fundamental entre a matéria humana e os demais objetos do mundo. Segundo essa lógica, nada distinguiria, em última instância, a constituição orgânica de um corpo humano de qualquer amontoado de utensílios descartáveis e banais. Restaria apenas a ideia do que é um ser humano, uma classificação racional. O empenho da humanidade em destacar-se da natureza (fabricando-a) é tensionado, redistribuindo poeticamente as moléculas que formam um corpo em sabonetes, palitos de fósforo e açúcar. Reverter a ontologia humana - como estratégia para desestruturar o universo descrito nas enciclopédias e manuais científicos -, isto é, dilacerar o antropomorfismo, implica libertar o corpo de sua ideia, destituí-lo do fardo da semelhança divina. Ao friccionar o antropomorfismo, Bataille evoca o ponto cego deixado pelo projeto humanista: o homem universal é subcapitalizado e reduzido ao valor de 25 francos.

O parágrafo supracitado compõe um dos dois verbetes para o termo homem presentes no Dicionário Crítico do quarto número da revista Documents, editada por Georges Bataille na França entre 1929 e 1930. Num total de quinze edições, a publicação trazia em seu subtítulo as palavras doutrinas, arqueologia, belas artes e etnografia, evidenciando a transversalidade de seu inclassificável conteúdo e a forma inusitada como articulava texto e imagem, ressignificando a hierarquia verbólatra e logogêntrica do discurso científico racional num jogo de montagens que ora apresenta rigor acadêmico, ora entrega-se ao devaneio poético. Fundada por Bataille, Georges Henri-Rivière e Carl Einstein, a revista contou com a colaboração de nomes proeminentes do campo artístico e intelectual daquele período, como Georges Braque, Marcel Duchamp, Pablo Picasso, Erwin Panofksy, Fritz Saxl e Pietro Toesca, além de Michel Leiris, dissidente surrealista e amigo íntimo de Bataille.

O Dicionário Crítico, presente a partir da segunda edição, destaca-se como uma das mais criativas propostas de experimentação poética da revista: verbetes organiza-

2 Verbete Homem do Dicionário Crítico, revista Documents nº 4 editada em 1929. Trad. de João Camillo Penna e Marcelo Jacques de Moraes para a edição brasileira. 2018, p.96. 
dos independentemente de qualquer ordem alfabética, temática ou cronológica, em tamanhos variáveis e temas que eventualmente se repetem. A partir de cada termo (boca, museu, rouxinol, metamorfose, espaço, arquitetura, escarro, informe e outros, que contabilizam trinta e nove verbetes, dos quais quinze são atribuídos a Bataille), os autores saboreavam livremente as possibilidades de sentidos contidas nelas.

No entanto, não foi essa arbitrariedade aparentemente caótica que fez com que o dicionário se constituísse, conforme as palavras de Yves-Alain Bois, como "um dos atos de sabotagem mais eficazes de Bataille contra o universo acadêmico e o espírito de sistema”. Pois se tal arbitrariedade não excluía, evidentemente, o acidente, o acaso, o arbitrário - ao contrário, estes estavam em seu próprio cerne -, ela também encerrava um rigor reflexivo que, ao reabilitar o "valor de uso" antropológico da imagem e da escrita, vinha também combater vigorosamente um certo estetismo formalista que germinava com força nos anos 1920 (MORAES, 2005, p.1).

O projeto de Bataille e de seus colaboradores na Documents propõe uma desconstrução do sistema racional e incita uma abertura às possibilidades poéticas do pensamento. Não é fortuita a recorrência de imagens de corpos desfigurados, decompostos e mutilados em suas páginas: elas evocam as cisões e transformações violentas da concepção do que é ser humano. O pensamento de Bataille, em cada um de seus verbetes, propõe pensar o outro lado, o duplo de cada coisa: a boca, órgão nobre, responsável pela fala e pelo canto, é também usada para escarrar, xingar e vomitar (BOIS; KRAUSS, 1997, p.47).

Não é por outra razão que Georges Bataille associa a origem do museu moderno ao desenvolvimento da guilhotina, apoiando-se na evidência histórica de que o primeiro museu - no sentido moderno da palavra, ou seja, a primeira coleção pública - teria sido fundado em 27 de julho de 1793, na França, pela Convenção. (...) Das cabeças guilhotinadas aos belos rostos expostos nas telas dos museus, das gravuras de decapitados aos álbuns de família burguesa (...), uma verdadeira obsessão em "fixar" a face do homem invadiu a sensibilidade europeia a partir das últimas décadas do século XVIII. Tratava-se então, como sintetizou Bataille, "de um obstinado esforço no sentido de reencontrar a figura humana". (MORAES, 2012, p.19).

Bataille, ao associar a lógica da fundação do museu às decapitações na guilhotina da Revolução Francesa, faz disparar, através de uma montagem, novos sentidos possí- 
veis para pensarmos esses dois termos. À assepsia clássica dos museus franceses, Bataille acrescenta uma outra camada de significado: uma vitrine de decapitados.

No final do século XVIII, durante os anos do terror, alguns gravuristas franceses passaram a dedicar-se a um gênero particular de representação da figura humana: o retrato do guilhotinado. Gesto último do ritual da execução, a exibição do rosto do decapitado pelo carrasco anunciava o triunfo do corpo político sobre seus traidores (...) (Idem, ibidem, p.17).

A figura do dicionário, tradicional veículo da razão que circunscreve e fixa o valor semântico de cada vocábulo, é apropriada para perturbar a ordem classificatória das palavras. Os verbetes da Documents, ao invés de explicar o sentido de cada palavra, propõem novas significações. O corpo da Idade Moderna, investigado exaustivamente e concebido como engrenagem na qual cada parte desempenha uma função, é o corpo-dicionário: o sentido dos olhos é ver, o sentido dos pés é andar. Um dicionário em crise é aquele em que suas unidades mínimas se rebelam contra a máquina. Os olhos podem nele ser ovos, os pés podem ser o instrumento da fala.

Em sua obra Livro de carne (figura 3), de 1978, Artur Barrio explora a possibilidade de se construir uma superfície perecível para a inscrição do pensamento. A carne, como matéria orgânica, tensiona a forma e perturba a finalidade de preservação do livro: um objeto feito de carne, se mantido em condições atmosféricas regulares, está fadado à mutação, ao processo de decomposição e aniquilamento. O livro, para que possa conservar as palavras, necessita de material sólido e seco; a assepsia das páginas de papel no livro é confrontada pela organicidade da carne.
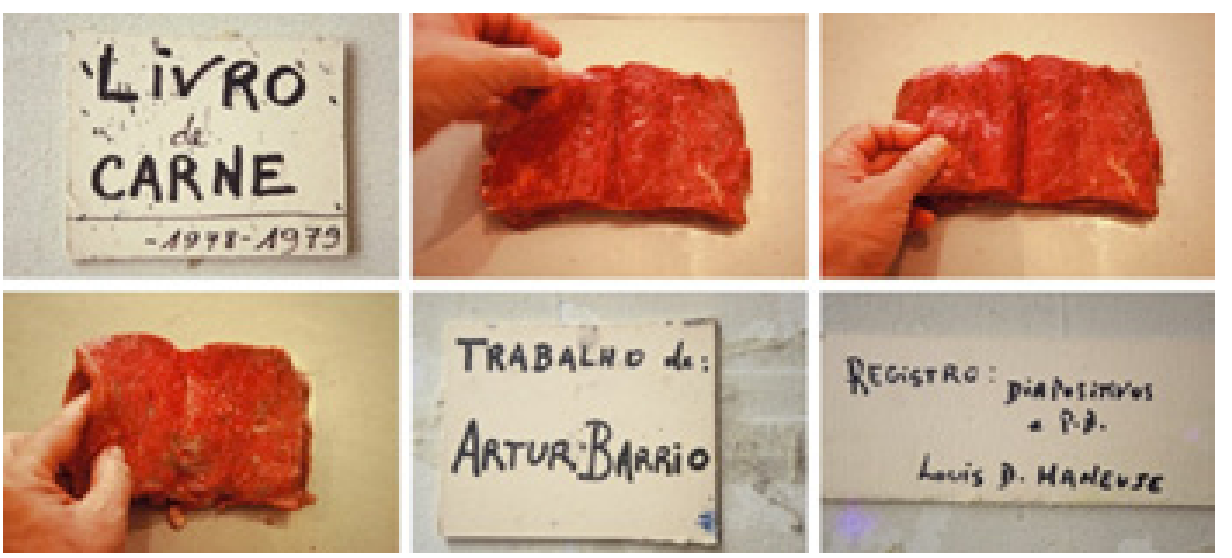

Figura 3. Livro de carne, Artur Barrio, 1978-9 
Fazer um Livro de Carne (1978/79) é uma ironia suprema, nesse sentido. O livro como lugar organizado do saber, da legitimação do conhecimento e da força do Logos; a carne como matéria bruta, viva, puramente sensória e pulsante. $\mathrm{O}$ Livro de Carne é uma tentativa de planejar o 'implanejável', de compor o 'incomponível', de alijar do livro os seus 'juízos finais'. O Livro de Carne é puro paradoxo, ato de desprogramar a razão pelo absurdo, de se infiltrar nas páginas da ordem, deletando sua lei (BARRIO, 2002, p.197).

A labilidade do objeto produzido em carne remete à própria definição de informe proposta por Bataille em 1929, no sétimo número da Documents:

Um dicionário começaria a partir do momento em que não fornecesse mais o sentido, mas as tarefas das palavras. Assim, informe não é apenas um adjetivo tendo tal ou tal sentido, mas um termo que serve para desclassificar, exigindo geralmente que cada coisa tenha sua forma. O que ele designa não tem seus direitos em sentido algum e se faz esmagar em toda parte como uma aranha ou um verme. Seria preciso, com efeito, para que os homens acadêmicos ficassem contentes, que o universo tomasse forma. A filosofia inteira não tem outra meta: trata-se de dar um redingote ao que é, um redingote matemático. Em compensação, dizer que a universo não se assemelha a nada e que ele sé é informe equivale a dizer que a universo é algo como uma aranha ou um escarro. (BATAILLE, 2018)

O informe surge como uma espécie de meta-verbete, que questiona o funcionamento da lógica do dicionário. Para Bataille, o racionalismo acadêmico, ao encerrar cada coisa à sua classificação, nega o outro contido nela. Para criar imagens do informe, o autor faz uso de figuras como a aranha e o escarro: a razão enciclopédica, que opera estabelecendo analogias e formando grupos, tipos e classes, é, para ele, negar que o universo não se assemelha a nada senão ele mesmo - imanente e singular. O corpo, em sua organicidade informe, funciona como ponto de partida para pensar os limites de cada objeto. No Dicionário Crítico, da figura humana ao informe, Bataille lança elementos que irão orientar seu pensamento sobre as imagens do corpo.

\section{O CORTÁVEL: A ENCRUZILHADA DE VIOLÊNCIAS PRIMORDIAIS}

Por tensionar o limite de sentido das coisas, o pensamento de Bataille é de valor seminal para pensar articulações possíveis entre as noções de corpo e transgressão. Segundo ele, a experiência humana é marcada pela descontinuidade - condição de existirmos como indivíduos diferenciados, apartados dos outros e do mundo - e que, 
através do fenômeno erótico, vislumbramos a possibilidade da continuidade - a comunhão, a indiferenciação, o todo. No êxtase, em oposição ao tempo do trabalho, dá-se a suspensão da identidade, ruptura da ilusão do Eu coerente, fechado. Bataille, ao relacionar o erotismo à morte, reflete sobre possibilidades de reconfiguração do Eu homogêneo em heterogeneidade, alteridade e diferença. A transgressão ocupa, na obra batailleana, o ponto de inflexão no qual o humano, como numa dobra, tem acesso ao outro que há nele próprio. Se Bataille propõe, em O Culpado, os termos acabamento e inacabamento para pensar o abismo que funda o contato entre dois indivíduos, em $O$ Erotismo, publicado duas décadas mais tarde, em 1957, o autor elabora esse impasse utilizando as expressões continuidade e descontinuidade. No pensamento batailleano, as pulsões de violência presentes nas decomposições e apagamentos da forma humana é elemento fundador de nossa vivência: através dela construímos e redefinimos incessantemente os limites de nossos corpos e de nossa individualidade.

O que disse permite captar nela a unidade do domínio erótico, aberta a nós por uma recusa da vontade de fechamento em si mesmo. O erotismo abre para a morte. A morte abre para a negação da duração individual. Poderíamos, sem a violência interior, assumir uma negação que nos conduz ao limite de todo o possível? Gostaria, para terminar, de ajudá-los a sentir plenamente o lugar a que quis conduzir, por pouco familiar que tenha por vezes podido lhes parecer, é entretanto a encruzilhada de violências fundamentais (BATAILLE, 2014, p.47).

A encruzilhada de violências fundamentais: o erotismo, como fenômeno humano, consiste na "aprovação da vida até na morte" (ibidem, p.35); uma vez que "o sentido último do erotismo é a fusão, a supressão do limite” (ibidem, p.153). A nostalgia da continuidade, alteridade mínima, no entanto, nunca se conclui senão pela morte, desaparecimento definitivo do indivíduo descontínuo. "Escrevo para apagar meu nome” (BATAILLE apud MORAES, 2005, p. 95): a célebre frase batailleana é ponto de partida de um projeto poético baseado na superação do Eu, transposição da memória individual em que a sublimação extática ganha contornos místicos. Bataille busca incessantemente romper as fronteiras e ultrapassar os limites da racionalidade para entrar em contato com o outro lado, acessar "a parte maldita”. "Esta exposição me põe em jogo pessoalmente”, escreve Bataille. Partindo daí, Osvaldo Fontes Filho propõe a questão: “em poucas palavras: a vida vista a partir da decomposição de todas as coisas, a partir da morte. Eis o cenário para que o Eu se escreva, uma última vez. Ou será um não-Eu que já fala em seu lugar?” (2007, p.44). 
O erotismo seria, em última instância, um fenômeno humano relacionado diretamente à consciência da morte. Diferentemente dos demais animais, o humano demonstra perceber, desde pelo menos o período paleolítico, o processo da morte e sua própria condição de finitude - afirmação que se evidencia no tratamento ritualístico e no sepultamento dos cadáveres de seus semelhantes. A transgressão que o erotismo opera se dá em tensão com o interdito da morte: são gerados mutuamente, cada qual prevê a existência do outro e dela depende. O erotismo, em Bataille, nada mais é que uma paródia da continuidade, sua simulação, do mesmo modo que, segundo ele em O Ânus Solar, de 1931, “o coito é a paródia do crime”. Esse processo se dá como se o temor e o fascínio da morte fossem elaborados em transgressões parciais.

A transgressão organizada forma com o interdito um conjunto que define a vida social. A frequência - e a regularidade - das transgressões não abala a firmeza intangível do interdito, de que é sempre o complemento esperado - como um movimento de diástole e sístole, ou como uma explosão é provocada pela compressão que a precede (...) Muitas vezes a transgressão do interdito não está ela própria menos sujeita a regras que o interdito. Não se trata de liberdade: em tal momento e até este ponto, isso é possível - esse é o sentido da transgressão. Mas uma primeira licença limitada pode desencadear o impulso ilimitado à violência: as barreiras não são simplesmente retiradas, pode mesmo ser necessário, no momento da transgressão, afirmar sua solidez (BATAILLE, 2013, p.89).

O Culpado compõe a segunda parte da Suma Ateológica, tendo, a princípio, um formato de diário no qual Bataille elabora três lutos: a morte de sua companheira Laure - Collete Peignot -, a dissolução do grupo em torno da revista Achépale e o início da Segunda Guerra Mundial. A palavra francesa coupable abre-se então para dois sentidos possíveis: culpado e cortável. O texto, confessional e angustiado, revela o sentimento de perda do autor, que, solitário, debruça-se sobre o vazio deixado por Deus. A substância do universo, pensada como estabilidade provisória - frágil equilíbrio que conecta todas as formas (que, para ele, não podem ser isoladas) -, surge como objeto central de reflexão na obra: um universo dilacerante.

Minha concepção é um antropomorfismo dilacerado. Não quero reduzir, assimilar o conjunto do que é à existência paralisada por servidões, mas à selvagem impossibilidade que sou, que não pode evitar seus limites, e tampouco manter-se neles. (...) Em toda realidade acessível, em cada ser, é preciso buscar o luar sacrificial, a ferida. Um ser só é tocado no ponto onde sucumbe (...). (Idem. 2018, p.47). 
Duas impossibilidades são elaboradas na concepção de antropomorfismo proposta por Bataille: a impossibilidade que se é e a impossibilidade de uma aniquilação integral. Se, para ele, as imagens do corpo - tomadas aqui como paródia da noção de humanidade - assumem caráter de abertura, ferida, indefinição, é para pontuar a labilidade dos limites humanos frente ao universo. A desfiguração humana não é produto exclusivo das experiências modernas oitocentistas, mas antes uma de suas manifestações possíveis.

Tudo acontece como se no horizonte de tal empreendimento não houvesse jamais um termo final e esse luto da imagem do homem, como propõe Didi-Huberman, nada mais fosse realmente que um interminável e irremediável processo. (...) a decomposição nunca encontra sua resolução no aniquilamento. O homem, diz Georges Bataille, “é o único animal que mata seus semelhantes com furor e obstinação"; porém, “ele é também o único que se transtorna de maneira absolutamente dilacerante com a morte de seus semelhantes". (...) a razão pela qual a figura humana não pode ser aniquilada por completo: se ela é aquilo que o homem destrói de forma mais feroz e obstinada, paradoxalmente ela representa também a imagem do que permanece indestrutível (MORAES, 2012, p.149).

A ideia de um antropomorfismo dilacerado não é, portanto, o apagamento completo da figura humana, mas, antes, o processo através do qual as imagens do corpo são desestabilizadas, perturbadas. A superação do antropomorfismo não se completa, mantendo-se o processo contínuo de desantropomorfização, do qual surgem outros corpos.

\section{POR UM ANTROPOMORFISMO DILACERANTE}

Dilacerar o antropomorfismo excede uma simples operação de ruptura física do corpo: a proposta de uma desantropomorfização é, antes, o tensionamento das estruturas discursivas que interpretam o mundo a partir de uma determinada possibilidade humana. Para tal, é preciso reavaliar as articulações que opõem, de um lado, o corpo e, noutro, transgressão, violência, repressão, disciplina etc. Não se trata aqui de considerar um corpo natural, em sua presumida essência e inteireza, que seria submetido a atos violentos que o destroem, mas de entender tal violência como parte constitutiva das noções de corpo. Ao pensar as relações de poder que atravessam os corpos, Roberto Machado afirma que esse "não destrói o indivíduo; ao contrário, o fabrica. O indivíduo não é o outro do poder, realidade exterior, por ele anulado; é um de seus mais impor- 
tantes efeitos"3. No campo artístico, espaço de disputa das narrativas, representações e expressões, o corpo ressurge como alvo de violências na medida em que se faz necessário reinventar sua imagem e repensar os discursos que o constroem e organizam. “Corpo diz inicialmente a distinção frente ao outro: o contorno onde começa e termina uma existência”, afirma Jean-Luc Nancy. "Existir significa distinguir-se tanto o nada como de outras existências. (...) Nunca há, portanto, um corpo sem outros corpos" $(2015$, p.7). A construção de corpos normativos relaciona-se diretamente à marginalização de corpos não-hegemônicos, numa contínua atualização que os põe em fricção. O processo de falência das imagens antropomórficas clássicas abre espaço para a emergência de outros corpos possíveis: Jota Mombaça (Monstrx Erratik), "bicha não-binária, nascida e criada no Nordeste do Brasil, que escreve, performa e faz estudos acadêmicos em torno das relações entre monstruosidade e humanidade", parte de questionamentos sobre violência, decolonialidade e queer para fazer visíveis opressões que recaem sobre seu corpo. Em suas ações Soterramento (2014) e Corpo-colônia (2013), Mombaça cria situações nas quais sua carne - fora dos padrões normativos de peso, etnia e gênero - sofre soterramentos com pedras e terra. Essa possibilidade periférica de corpo, historicamente marginalizada, apropria-se dos mecanismos que a oprimem para construir uma poética crítica e deliberadamente violenta.

Outro exemplo é a performance Sem Título/Limite Zero, realizada por Berna Reale em 2011, na qual a artista é carregada nua por dois homens vestidos como açougueiros pelas ruas de Belém. Berna desvela a tensão intrínseca à exibição do corpo feminino em situação de submissão, cuja invisibilização decorre de uma rede de violências simbólicas. A representação do corpo da mulher, tradicionalmente ligada à posse - corpos dóceis e disponíveis para o olhar masculino - ressurge colocando-se em situação de violência para tornar visíveis estruturas silenciosas de violência.

O dilaceramento do antropomorfismo clássico, que descentraliza a visibilidade dos corpos, cria também possibilidades de rearranjamentos. É o caso da obra do alemão Hans Bellmer, célebre por suas imagens de corpos cujas partes recompõem-se em estruturas perturbadoras na década de 1930: bonecas em que pernas ganham o lugar de braços e cabeças podem ocupar a porção baixa do corpo. Há nessas reconfigurações

3 MACHADO, R. Introdução. In: FOUCAULT, M. Microfísica do Poder. $5^{\mathrm{a}}$ edição. Rio de Janeiro: Paz e Terra, 2017 . 
uma estreita articulação com o pensamento de Paulo de Tarso ${ }^{4}$, pervertendo-o, uma vez que os diferentes elementos do corpo reorganizam-se anarquicamente, reclamando uma recomposição dos sentidos. Fenômeno similar ocorre em Polvo (2000), do carioca Michel Groisman, que consiste num baralho no qual cada carta apresenta a imagem de uma parte do corpo. O público é convidado a formar novas combinações entre os elementos de modo a compor corpos híbridos.

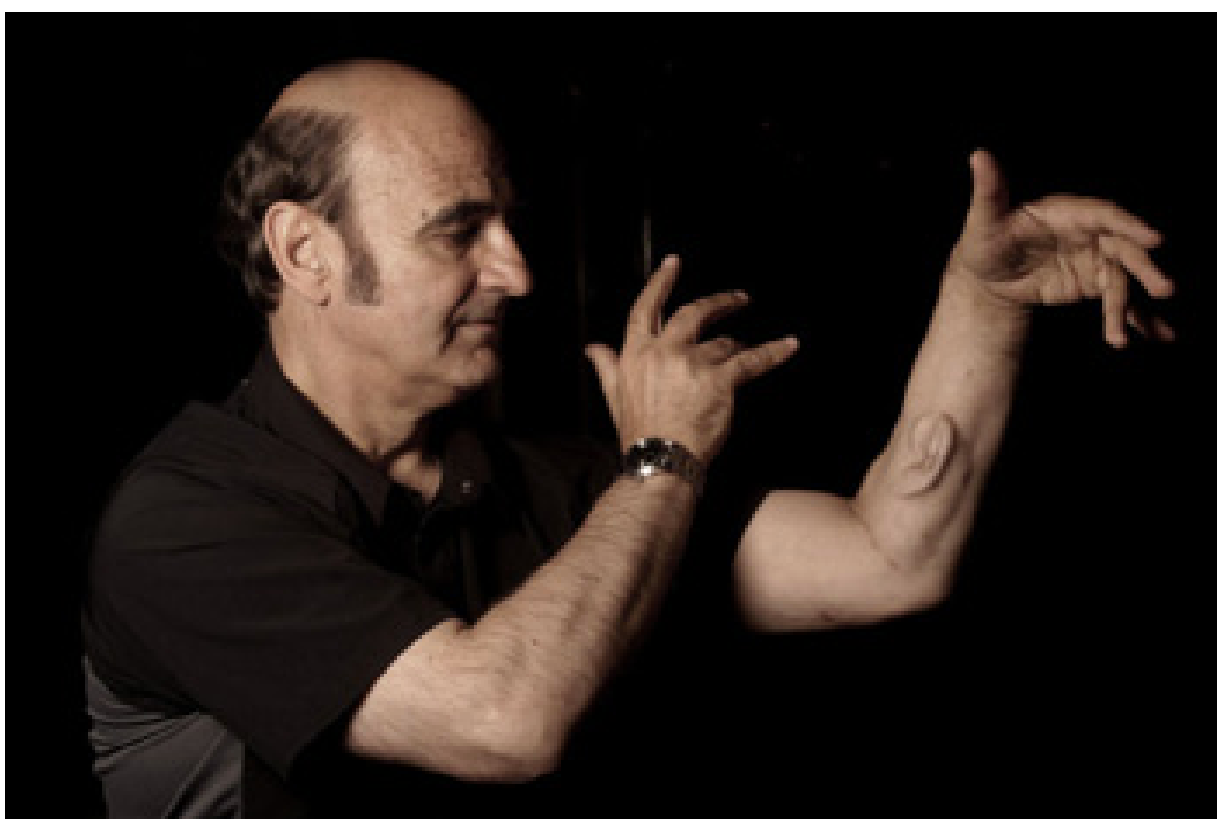

Figura 4. Ear on arm, Stelarc, 2007

O artista australiano Stelarc, célebre por suas poéticas transgressoras - como a série de obras nas quais seu corpo é suspenso por ganchos cravados em sua pele -, apresenta em 2007 o projeto de criar uma orelha em seu próprio braço. Ao longo de doze anos, duas cirurgias foram realizadas para aplicar o órgão no qual, moldado a partir de réplicas produzidas a partir de suas células, pretendia-se instalar um microfone. Ear on arm (figura 4) leva às últimas consequências a desagregação do corpo, construindo um antropomorfismo outro. Se para a razão anatômica as partes do corpo devem resignar-se às suas posições e funções, Sterlac perverte a organização normativa, propondo um corpo inédito.

4 Paulo de Tarso, apóstolo cristão, retoma ideias do direito romano (na qual a sociedade tem funcionamento análogo ao do corpo, distribuindo hierarquicamente determinadas atribuições a cada uma de suas partes) para pensar a organização da Igreja. Segundo ele, cada partícula deste corpo deve cumprir seu dever sem contestá-lo, para que assim o organismo funcione corretamente: "Se o corpo todo fosse olho, onde estaria o ouvido? E se fosse todo ouvido, onde estaria o olfato?” (Co 12,17). 
Em meio à multidão de corpos que, como capilaridades, criam-se e são criados na fricção entre real e ideal, a contemporaneidade faz surgir antropomorfismos dilacerantes que não apenas reclamam espaço para corpos existentes, mas inventam novos corpos. “Negar o possível para imaginar o impossível: o projeto de G. Bataille, ao mesmo tempo em que remete aos fundamentos da liberdade da imaginação, resume o sentido último de seu antropomorfismo dilacerado, insistindo em repensar o homem a partir do nada", nos diz Eliane Robert Moraes (2012, p.227). Reconstruir o corpo, pensado como algo que não é dado ou natural, presume a violência de um desantropomorfismo que jamais se conclui.

\section{REFERÊNCIAS BIBLIOGRÁFICAS}

BATAILLE, Georges. A parte maldita. Belo Horizonte: Autêntica, 2016.

Documents: Georges Bataille. Florianópolis: Cultura e Barbárie, 2018.

. O Culpado. Belo Horizonte: Autêntica, 2017.

O erotismo. Belo Horizonte: Autêntica, 2014.

BOIS, Yve-Alain; KRAUSS, Rosalind. Formless : a user's guide. Nova York : Zone Books, 1997.

CANONGIA, Ligia (org.). Artur Barrio. Rio de Janeiro: Modo, 2002.

D’AGOSTINO, Mário Henrique Simão. A arquitetura, o corpo e o espelho sobre a beleza e o tempo na arte do Renascimento e em nossos dias. Tempo Social. São Paulo: USP, vol. $15, \mathrm{n}^{\mathrm{O}} 1$, abril $/ 2003$.

DIDI-HUBERMAN, Georges. A semelhança informe: ou o gaio saber visual segundo Georges Bataille. Rio de Janeiro: Contraponto, 2015.

FOUCAULT, M. Microfísica do Poder. $5^{\mathrm{a}}$ edição. Rio de Janeiro: Paz e Terra, 2017.

MORAES, Eliane Robert. O Corpo Impossível. São Paulo: Iluminuras, 2012.

MORAES, Marcelo Jacques. Georges Bataille e as formações do abjeto. Outra Travessia (UFSC), Florianópolis, p. 107-120, 2005.

NANCY, Jean-Luc. Corpo, fora. Rio de Janeiro: 7Letras, 2015. 